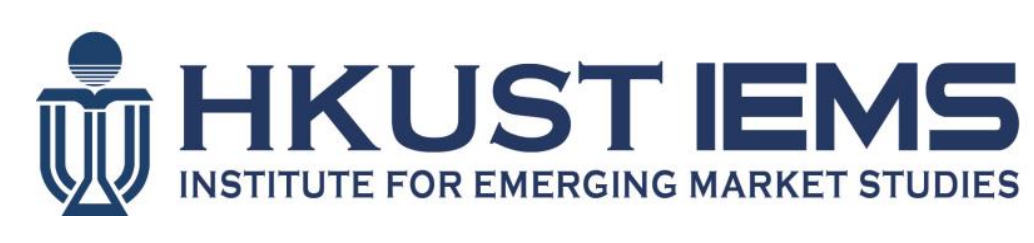

\title{
Is the PDS Already a Cash Transfer? Rethinking India's Food Subsidy Policies
}

\author{
Sujata BALASUBRAMANIAN
}

HKUST IEMS Working Paper No. 2015-16

March 2015

HKUST IEMS working papers are distributed for discussion and comment purposes. The views expressed in these papers are those of the authors and do not necessarily represent the views of HKUST IEMS.

More HKUST IEMS working papers are available at: http://iems.ust.hk/WP 


\title{
Is the PDS Already a Cash Transfer? Rethinking India's Food Subsidy Policies
}

\author{
Sujata BALASUBRAMANIAN
}

HKUST IEMS Working Paper No. 2015-16

March 2015

\begin{abstract}
Critics argue that India's mismanaged Public Distribution System (PDS), which sells subsidized cereals to poor families, should be replaced by cash transfers. Others fear cash may be misused. Using National Sample Survey data, this paper demonstrates that families treat additional PDS subsidies wholly as a source of cash - exactly like a cash transfer. More worryingly, cereal consumption has not increased, despite higher real subsidies. Moreover, neither the PDS nor cash transfers are likely to raise total food expenditure in poor families. Finally, therefore, the paper explores how higher food consumption and other objectives of PDS subsidies may be achieved.
\end{abstract}

\section{Author's contact information}

Sujata Balasubramanian

Division of Social Science

The Hong Kong University of Science and Technology

Hong Kong

E: sujata@ust.hk 


\title{
Is the PDS already a cash transfer? Rethinking India's food subsidy policies
}

\begin{abstract}
Critics argue that India's mismanaged Public Distribution System (PDS), which sells subsidized cereals to poor families, should be replaced by cash transfers. Others fear cash may be misused. Using National Sample Survey data, this paper demonstrates that families treat additional PDS subsidies wholly as a source of cash exactly like a cash transfer. More worryingly, cereal consumption has not increased, despite higher real subsidies. Moreover, neither the PDS nor cash transfers are likely to raise total food expenditure in poor families. Finally, therefore, the paper explores how higher food consumption and other objectives of PDS subsidies may be achieved.
\end{abstract}

\section{Introduction}

India’s Public Distribution System (hereafter, PDS), is a nation-wide network for the distribution and sale of subsidized foodgrains, targeted mainly at poor households. Research has indicated however, that as much as 55 percent of the grain may be illegally diverted by intermediaries, so that poor families receive a much lower quantity of cereals ${ }^{1}$ than they are entitled to (Jha and Ramaswami, 2010). The Indian Planning Commission’s own calculations indicate that the costs of corruption and inefficiency in the PDS may be as high as 70 per cent (Kapur et al., 2008). Other estimates are even higher, suggesting that the government spends nine rupees for every single rupee transferred to poor households (Svedberg, 2012) or that only about 10 percent of the total subsidy reaches the poor (Jha and Ramaswami, 2010).

This evidence of large-scale mismanagement has caused a heated debate about the future of the system. Critics argue that the PDS should be scrapped and that poor households would receive a much higher percentage of these food subsidies if the government simply gave them cash (Kapur et al., 2008; Kotwal et al., 2011;

Svedberg, 2012). Advocates of the PDS, on the other hand, claim that it can be successfully reformed, given the political will (Dreze and Khera, 2011; Khera, 2011b; 
Puri, 2012). The first point of disagreement between these opposing groups is therefore about which of the two - a reformed PDS or a switch to cash transfers would be a more efficient way of delivering the subsidy.

A second point of disagreement relates to the use of the food subsidy. Those in favour of cash transfers claim that the potential for wasteful spending or misuse of cash is not large, especially if the transfers are made to women (Kapur et al., 2008; Kotwal et al., 2011). In contrast, supporters of the PDS point out that many female beneficiaries are strongly against a shift to cash transfers, precisely because they fear that the money may be misused or spent on needs other than food (Ghosh, 2011; Puri, 2012). Thus, Ghosh (2011) observes that 99 per cent of women in a Delhi slum area preferred to receive food rations, rather than cash, because they were afraid that cash might be spent on other immediate needs or even on celebrations and alcohol. Groups like the 'Right to Food Campaign', which is concerned about the high rates of malnutrition in the country, have been particularly active in opposing cash transfers and calling for the continuation and expansion of the PDS (Right to Food Campaign, 2011, 2013).

This paper seeks to bring a fresh perspective to this ongoing debate by demonstrating that:

1) The PDS already functions just like a cash transfer to poor households households treat additional PDS subsidies entirely as a source of cash.

2) The PDS has signally failed to increase cereal consumption in poor families, in spite of giving them substantially larger quantities of grain and higher real subsidies over time.

3) Neither a reformed PDS nor a switch to cash transfers is likely to raise either cereal consumption or total food expenditure in poor households. 
Prior research on the subject has focused either on general trends in cereal consumption in India or specifically on the PDS, and, for the most part, these two issues have not been explicitly linked. By assessing how the PDS has affected both cereal consumption and total food expenditure in poor families, this paper aims to provide an integrated picture of the role that the PDS plays in the consumption patterns of its target households.

Using National Sample Survey (NSS) data for the period 1999-2000 to 20092010, the paper illustrates the three points above. To elaborate: it shows, firstly, that poor families have treated the PDS as a source of cash - utilizing all cash saved due to additional cereal subsidies for spending on goods and services other than cereals. Secondly, while even a cash transfer would be expected to increase cereal consumption, due to the creation of positive income effects, higher PDS subsidies have failed to raise cereal consumption, in spite of coinciding with both a rise in real incomes in poor families and a relative fall in the market price of cereals. In other words, the marginal propensity of poor households to consume foodgrains out of PDS subsidies appears to be zero.

Thirdly, the analysis shows that both the PDS and cash transfers are also unlikely to cause poor families to increase total expenditure on food. While the PDS made much higher real transfers to poor households between 1999-2000 and 20092010, three-fourths of these households actually reduced real expenditure on food, spending all increases in real income on non-food goods and services. In the remaining one-fourth of households too, increases in real income were overwhelmingly devoted to non-food expenditure.

These results indicate that if the goal of the PDS subsidies is to increase food consumption in poor families, then neither a reformed PDS nor a switch to cash 
transfers is likely to be effective. Consequently, any proposal for reforming the PDS must begin by addressing the question of exactly what objectives it is intended to achieve. Accordingly, this paper identifies three major roles that the PDS has been expected to play - as a price stabilization and distribution system, as a safety net, and as a nutrition programme - and explores the extent to which reform can help to achieve the desired outcomes in each case.

The rest of the paper is organized as follows: Section 2.1 briefly discusses the mechanisms by which the PDS is expected to increase cereal consumption in poor households. Section 2.2 provides the background for the data analysis, describing relevant changes in PDS subsidies and cereal consumption in India. In Sections 2.3 and 2.4, National Sample Survey (NSS) data is used to analyze the actual patterns of cereal consumption and total food expenditure in poor households over an eleven year period. Section 3 identifies the major objectives of the PDS and suggests options for reform in line with the findings from Section 2. Finally, Section 4 concludes.

\section{The PDS and food consumption in poor, Indian households: an analysis}

\subsection{How are PDS subsidies expected to increase cereal consumption in poor families?}

Since cash is fungible and may be spent on goods and services other than food, governments have typically preferred to provide food assistance to poor households by distributing food stamps or food rations (Currie and Gahvari, 2008). However, when the quantity of food rations or the value of food stamps provided to a household is infra-marginal - less than the household's planned consumption of food 
- the provision of in-kind food transfers no longer acts as a constraint on household spending. Households can simply reduce their market purchases of food as needed to offset these government transfers, thereby keeping overall food consumption at the desired level. Consequently, economic theory predicts that, as long as transfers are infra-marginal, households will spend exactly the same total amount on food irrespective of whether they are provided with cash transfers or equivalent food stamps/food transfers (Southworth, 1945).

The provision of subsidized cereals by the PDS may be seen as a form of inkind food assistance to poor families, similar to food rations or food stamps. If the quantity of subsidized grain provided by the PDS is extra-marginal (greater than a household's planned consumption), then the resulting fall in the relative price of cereals should, ceteris paribus, induce increased cereal consumption because of both substitution and income effects, assuming that cereals are a normal good. However, if the quantity of grain provided by the PDS is infra-marginal, then, theoretically the PDS becomes equivalent to a cash transfer, as described above (see also Khera, 2011a for a graphical exposition of this point). Nevertheless, other things being equal, this cash transfer via the PDS would still be expected to lead to higher cereal consumption in poor households, through the creation of positive income effects.

While economic theory maintains that there should be no difference between the PDS and cash transfers when the quantities of grain provided by the PDS are infra-marginal, the empirical evidence suggests otherwise. A large number of empirical studies in the United States have shown that poor households display a much higher marginal propensity to consume food out of food stamps than out of increases in cash income, although food stamp provision is infra-marginal for roughly 85 to 95 percent of these households (Breunig et. al., 2001). This phenomenon has 
been termed the 'cash-out puzzle' and the results support the view that a move from food stamps or food rations to cash transfers is likely to reduce food consumption in poor households (Breunig et. al., 2001). Similar effects have also been uncovered in Bangladesh, when food and cash transfers are compared (Ninno and Dorosh, 2003; Ahmed 2005).

The empirical evidence thus indicates that poor households may react differently to the provision of food rations or food stamps than to cash transfers, even when these transfers are infra-marginal. Consequently, it could be hypothesized that PDS subsidies should lead to larger increases in cereal consumption than would occur with equivalent cash transfers to poor families, even if the PDS provides only inframarginal quantities of grain.

\subsection{Background of PDS subsidies and cereal consumption in India}

Until the late nineties, the PDS provided food subsidies to the general population. However, in 1997, it was restructured into a 'targeted' system with subsidies targeted directly at poorer households. Currently, therefore, the extent of the subsidy depends on whether a household is classified as being 'Antyodaya' (AAY or 'Poorest of the Poor'), 'Below Poverty Line' (BPL) or 'Above Poverty Line' (APL)². APL households are expected to pay the full 'economic cost' for foodgrains; while poorer AAY and BPL households receive the largest subsidies (see World Bank, 2011 for details).

This targeting process has itself been subject to problems and there have been serious errors both of inclusion and exclusion. Critics point out that many poor households have failed to benefit because of incorrect classification, while non-poor households receive a significant part of the subsidy (Khera, 2011b; Svedberg, 2012). 
Accordingly, this paper does not rely on the official classification of households into the categories of BPL, APL and AAY in order to identify the poor. Instead, I have categorized households as poor based on the results of the National Sample Survey (NSS) - 'poor households' are defined as those in the bottom four deciles of the population in terms of monthly per-capita expenditure (MPCE), according to the NSS statistics.

The data analysis in Section 2.3 seeks, firstly, to verify whether poor households, as defined above, have actually received larger quantities of subsidized grain and higher real transfers as a consequence of the new, targeted PDS. This verification of actual benefits received by poor families from the PDS is very important because of both the targeting errors described above and the widespread illegal diversion of PDS foodgrains mentioned earlier.

Secondly, the analysis tries to assess how the distribution of subsidized foodgrains by the PDS has affected total cereal consumption in these poor families. Most previous research has not explicitly linked cereal provision by the targeted PDS to the cereal consumption of poor households, exceptions being the work by Kochar (2005) and Svedberg (2012).

Kochar's (2005) study covers a 2-3 year period after the introduction of the targeted PDS, but excludes several major Indian states and includes only rural, not urban, households. This paper, however, utilizes all-India data, covering all states, and both urban and rural households, over a later, 11-year period. Nevertheless, Kochar's (2005) conclusion, that the PDS has had only a marginal effect on the calorie intake of the poor, is similar to the results of this paper. However, while Kochar (2005) attributes the lack of impact to poor households not receiving sufficient quantities of grain from the PDS, this paper shows that poor households received both substantially 
larger quantities of grain and higher real transfers from the PDS, over the relevant time period.

Svedberg (2012) analyzes data from the year 2004-2005, and observes that cereal consumption in poor, BPL/AAY households is slightly (though not significantly), lower than in poor households which do not hold BPL/AAY cards - he concludes that the PDS does not improve food security or nutrition. Importantly, however, Svedberg (2012) also suggests two plausible, alternative explanations for his results. First, he correctly notes that BPL/AAY households may be poorer than other 'poor' households (those in the bottom three MPCE deciles). This explanation is, in fact, supported by NSS data for 2004-2005 (see NSSO, 2007), suggesting that lower incomes could indeed be the reason for the lower cereal consumption of BPL/AAY households vis-à-vis other 'poor’ households. Secondly, Svedberg (2012) speculates that BPL/AAY households may treat PDS subsidies like income transfers and perhaps use them to buy non-cereal foods - he calls for further research to investigate these issues.

As mentioned in the Introduction, this paper provides the evidence needed to answer these important questions raised by Svedberg (2012) - showing clearly that the PDS has not raised cereal consumption despite providing higher real subsidies (and despite both higher incomes and lower relative cereal prices). The longitudinal analysis presented in this paper also establishes that poor households treat PDS subsidies like a cash transfer. Contrary to Svedberg's (2012) speculation, however, this analysis shows that households do not use this cash transfer to increase real food expenditures - leading to the conclusion that neither a reformed PDS nor cash transfers are likely to improve nutrition. 
In another, related, stream of research, several scholars have identified a longterm trend of declining average cereal intake in India, beginning from the early 1970s (Radhakrishna, 2005; Rao, 2005; Kumar et al., 2007; Deaton and Dreze, 2009). These researchers also show declines in cereal consumption among poorer households for varying time periods starting from the 1980s, with one study showing declines in the poorest rural quartile between 1983 and 2004-2005 (Deaton and Dreze, 2009). However, none of the studies looks at the changes in PDS grain provision to poor households, during the time periods in which their cereal consumption fell: an issue which is critical to this paper's main argument. Consequently, it is possible that an increase in grain provision by the targeted PDS to poor families, after 1997, may have raised cereal consumption in these families in the subsequent period - a hypothesis tested by this paper.

Setting aside this issue of PDS provision of cereals, the trend of declining average cereal consumption in Indian households has been attributed to various factors. These may be broadly classified into two sets: firstly, explanations unrelated to changes in prices and real incomes, and secondly, relative price and income effects. The first set of explanations includes factors such as a reduction in physical labour (Rao, 2005; Deaton and Dreze, 2009), and changes in tastes and preferences (Sen, 2005; Kumar et al., 2007).

The second set of explanations suggests that the long-term average decline in cereal consumption may be due to a rise in the relative price of cereals (Mittal, 2007) or a fall in real incomes (Patnaik, 2010). This set of explanations is of particular relevance for the current analysis because, as mentioned earlier, the targeted PDS is expected to increase total cereal consumption in poor households by creating substitution and/or income effects. A rise in relative cereal prices or a fall in real 
incomes could potentially offset any positive effects created by the PDS: therefore, both these variables are central to the data analysis in Section 2.3.

\subsection{Analysis of National Sample Survey (NSS) data: have PDS subsidies increased cereal consumption in poor households?}

The data presented here includes figures from the NSS rounds of 1999-2000, 2004-2005 and 2009-2010. It covers an 11-year time period. The targeted PDS was in operation throughout this period.

A preliminary look at the data reveals that the quantities of subsidized grain provided by the PDS to poor families are infra-marginal and do not exceed 27 percent of the total household consumption of cereals, in any year (see Row 2 of Tables 1 and 2 respectively). Consequently, economic theory suggests that the PDS cannot create substitution effects and may only be expected to influence cereal consumption in poor households by creating positive income effects. Nevertheless, the 'cash-out puzzle' suggests that the PDS may also be able to increase cereal consumption in poor households because of their differential reaction to food versus cash transfers.

This section aims to determine whether the provision of subsidized cereals by the targeted PDS has led to an increase in the total cereal consumption of poor households over the period $1999-2000$ to $2009-2010$. Therefore, it is necessary to confirm that the following conditions have been satisfied:

1) The targeted system has actually enabled poor households to buy a larger quantity of subsidized cereals over this period, as opposed to simply increasing their entitlements on paper.

2) The targeted PDS has resulted in larger real income transfers to poor families between 1999-2000 and 2009-2010. Note that the value of the (imputed) 
income transfer to a family depends on both the difference between PDS prices and open-market prices as well as the quantity of grain the family is able to buy from the PDS.

3) The market price of cereals has not increased relative to both the overall food price index and the general price index. Since the PDS provides only inframarginal quantities of grain, households are still paying market prices for each additional unit of grain they buy. An increase in the market price of cereals, relative to other prices, would therefore be expected to create a substitution effect away from cereals thus reducing cereal consumption, as suggested by Mittal (2007).

4) The real income of these households has not fallen. A fall in real income would cause poor families to cut back on all consumption, including cereal consumption, as suggested by Patnaik (2010).

Conditions 1 and 2 aim to verify whether the targeted PDS actually provided greater real benefits to poor households between 1999-2000 and 2009-2010. On the other hand, conditions 3 and 4 are intended to rule out the two factors which could directly offset any benefits provided by the PDS and cause cereal consumption in poor households to fall.

5) If all four conditions above have been satisfied then, ceteris paribus, cereal consumption in poor households should have increased over the period, due to the targeted PDS. Fifthly, therefore it needs to be verified whether this has actually been the case - that is, whether total cereal consumption in poor households was higher in 2009-2010 than it was in 1999-2000. 


\section{Explanatory Notes to the data}

a. MPCE and 'poor households': The NSS reports categorize households into different classes based on their Monthly Per-Capita Expenditure (MPCE). In line with the definition of 'poor households' proposed earlier, this analysis focuses only on the bottom four MPCE deciles.

b. Cereals - PDS and market: Since rice and wheat are the only two grains widely distributed by the PDS, only these two cereals have been included in the calculations of cereals bought from the PDS. All other cereal consumption is assumed to be at market prices.

c. Price Indices: The commonly used price indices, for poor households in rural and urban India, are the Consumer Price Index for Agricultural Labourers (CPIAL) and the Consumer Price Index for Industrial Workers (CPIIW), respectively and these have been used throughout.

d. 'Unit Value' cereal prices: The prices of rice, wheat and (all) cereals utilized here have been calculated from NSS data as unit values ${ }^{3}$ (for a discussion regarding the validity of using unit values as prices see Deaton, 2008).

\section{INSERT TABLES 1 AND 2 HERE}

Tables 1 and 2 present the analysis for poor households in rural and urban areas, respectively and contain:

- $\quad$ Actual quantities of grain purchased from the PDS

- $\quad$ The resulting (imputed) income transfers from the PDS

- $\quad$ Changes in market prices of cereals and other goods

- $\quad$ Changes in real incomes in poor households and

- $\quad$ Changes in total cereal consumption in poor households. 
These calculations allow verification of the performance of the PDS in terms of the five conditions listed earlier. To begin with, condition 1 requires an increase in the quantities of cereals purchased from the PDS. A look at Tables 1 and 2 shows that the quantities of rice and wheat purchased from the PDS per-capita, per-month have increased, both in absolute terms (Row 1) and as a percentage of the total quantity of cereal purchases (Row 2). This is true for all of the four lowest MPCE deciles and in both rural and urban areas (Tables 1 and 2, respectively).

For example, for households in the first rural MPCE decile, the quantity of PDS rice and wheat purchases increased by 172 per cent from 1.02 kgs to $2.76 \mathrm{kgs}$ between 1999-2000 and 2009-2010. Simultaneously, the ratio of PDS grain purchases to total cereal kgs bought by these rural households rose from just under 10 percent to almost 27 percent. These figures demonstrate that poor households have actually been able to buy a larger quantity of subsidized cereals from the targeted PDS, rather than simply getting higher allotments on paper - thus satisfying condition 1.

Note that since the National Sample Survey (NSS) reports do not provide standard deviations, it was not possible to conduct tests for significance. However, the very large samples used in the surveys would make it relatively easy to obtain significance, thus rendering the size of the effects more important. This analysis has therefore focused on verifying that there have been substantial increases, in both the quantities of foodgrains purchased from the PDS (condition 1), and especially in the real income transfers from the PDS (condition 2). For conditions 3, 4 and 5, as shown later, the changes in the related variables have actually been in the opposite direction to that expected, so the tests of significance are no longer relevant.

Turning now to condition 2, regarding an increase in real income transfers from the PDS: I first present the nominal income transfer from the PDS in Row 3 and 
subsequently convert this nominal figure into two different real estimates. The nominal income transfer represents the cash saved by households due to their ability to buy grain from the PDS at lower-than-market prices and is the sum of the transfers arising from PDS purchases of rice and wheat ${ }^{4}$.

The real income transfer to households is shown, firstly, in Row 4, in constant 1999-2000 rupees per-capita. Secondly, the real income transfer is also calculated in Row 5 in terms of the additional kgs of cereals per-capita a household could buy with the nominal income transfer at the prevailing market price for cereals.

From Rows 3, 4, and 5 it is clear that both the nominal and real income transfers from the PDS have increased substantially, for all four bottom deciles and in both rural and urban areas. Both in constant 1999-2000 rupees (Row 4) and in terms of cereal kgs that could be purchased at current market prices (Row 5), real income transfers have roughly tripled for all deciles except for the top two urban deciles in which transfers more than doubled. In sum, the targeted PDS has made much larger real income transfers to poor households over the 11-year period - thus satisfying condition 2.

Turning next to condition 3, regarding relative cereal prices: Row 6 of Tables 1 and 2 presents indices of market cereal prices for households in each decile. These can then be compared to both the General and Food price indices of the CPIAL and CPIIW, for rural and urban households, respectively.

From Table 1 it can be seen that, for the bottom four deciles in rural areas, over the period 1999-2000 to 2009-2010, the index of the market price of cereals rose by only 61 to 63 percent (Row 6), while both the general CPIAL price index and the CPIAL food price index rose by 72 percent (Rows 7 and 8 respectively). Table 2 shows that over the same period, poor, urban households saw the market price of 
cereals rise by 65 to 76 percent, while the general CPIIW price index rose by 80 percent and the CPIIW food price index by 85 percent. It is clear, therefore, that the open market price of cereals for these poor households did not increase, relative to the price of food generally or relative to the price of other goods - thus satisfying condition 3.

Turning, lastly to condition 4: the possibility of a fall in real income over the period needs to be excluded, since this could have led poor households to cut back on various expenditures, including cereal consumption. Using real monthly per-capita expenditure (MPCE) as a proxy for real income, it can be seen, from Row 9 that this possibility is clearly ruled out by the data. Over the period 1999-2000 to 2009-2010, total real MPCE increased by approximately 8 to 10 percent for poor households in rural areas (Table 1) and by roughly 6 to 12 percent for poor, urban households (Table $2)^{5}$. Since real income has actually increased for all these poor households, rather than falling, condition 4 has also been satisfied ${ }^{6}$.

Accordingly, it is now possible to turn to condition 5, to verify if the higher benefits provided by the PDS have increased total cereal consumption in poor households ${ }^{7}$.

Unfortunately, as Row 10 of Tables 1 and 2 shows, for every single decile in both rural and urban areas, total cereal consumption has declined over the period 1999-2000 to 2009-2010. For the first decile in both rural and urban areas, this fall is fairly small, while for the three upper deciles the fall ranges from 7 to 11 percent. Cereal consumption has not increased in any decile, either rural or urban: in other words, condition 5 has not been satisfied ${ }^{89}$.

Thus, the analysis shows that the targeted PDS has failed to increase cereal consumption, in spite of providing much larger benefits to poor households and 
giving food assistance in kind rather than cash. For households in the first rural decile, for example, Table 1 shows that nominal income transfers from the PDS rose from Rs. 4.68 to Rs. 28.11 between 1999-2000 and 2009-2010 (Row 3), allowing them to increase monthly cereal consumption by 1.56 kgs per capita over this period (Row 5). Instead, these households treated this entire increase of Rs. 23.43 as cash which they could use for spending on other goods and services, while reducing total cereal consumption by 0.19 kgs per capita (Row 10).

\subsection{The PDS as cash transfer: changes in food and non-food expenditure}

The analysis in the previous sub-section shows, firstly, that the targeted PDS has functioned exactly like a cash transfer to poor families. Households have not used higher PDS subsidies on cereals to increase their cereal consumption, but have instead treated the PDS as a source of cash: utilizing all cash savings from additional PDS subsidies for spending on goods and services other than cereals. To that extent, therefore, the issue of whether the PDS or cash transfers should be the vehicle for cereal subsidies, may be irrelevant.

Secondly, even a cash transfer should have raised cereal consumption in poor households, through the creation of positive income effects. The failure of the PDS to do so indicates that the marginal propensity of poor families to consume cereals out of PDS subsidies may be zero. Consequently, even if the PDS is successfully reformed to provide much larger quantities of subsidized grain to poor families, it is not likely to lead to higher cereal consumption. And since the PDS is already being treated just like a cash transfer by poor households, a switch from the PDS to cash transfers is equally unlikely to raise cereal consumption. 
Since there was no relative increase in the market price of cereals between 1999-2000 and 2009-2010, and poor families also experienced a rise in real incomes during this period, the decision by these families not to increase cereal consumption must be attributed to factors other than relative prices and income. Some of these factors - such as changes in tastes and preferences and a reduction in physical labour were cited in Section 2.2. While poor families may have chosen not to increase cereal consumption because of these other factors, this does not negate the fact that malnutrition rates in India remain very high by international standards. As Deaton and Dreze (2009) point out: ‘anthropometric indicators of nutrition in India, for both adults and children, are among the worst in the world' (Deaton and Dreze, 2009, p. 42). It cannot, therefore, be assumed that the current cereal intake of poor households in India is adequate to meet their nutritional needs.

Of course, nutrition levels are influenced not just by cereal consumption, but by overall food intake, including the consumption of meat, milk, vegetables and all kinds of foods. Therefore, if poor households do not spend any of the increase in their real incomes (from the PDS and other sources), on buying cereals, it becomes meaningful to ask whether they spend it on buying other kinds of foods - as suggested by Svedberg (2012). From a policy perspective, it would, in particular, be valuable to know what percentage of increases in real income is spent on food and what percentage on non-food goods and services. Since the PDS is being treated essentially as an income transfer, this would provide an indication of how beneficial either PDS subsidies or cash transfers are likely to be in raising overall food consumption in poor households.

This question is addressed by comparing real food and non-food expenditures by poor households, over the period 1999-2000 to 2009-2010. As before, real 
Monthly Per-Capita Expenditure (MPCE) in poor families is used as a proxy for real income. The results are presented in Tables 3 and 4 for rural and urban families respectively: they show that three-fourths of poor households actually reduced real food expenditure during this period, in spite of increases in their real income.

\section{INSERT TABLES 3 AND 4 HERE}

Table 3 shows that in poor, rural households, practically the entire increase in real income (MPCE) has gone towards non-food goods and services, with spending on food shrinking as a percentage of the total household budget (Row 3). Between 1999-2000 and 2009-2010, the bottom four rural deciles saw increases in real MPCE ranging from about 8 to 10 percent. However, real food expenditure actually decreased marginally in the first and fourth deciles and increased by only about half to one percent for the second and third deciles. Real non-food expenditure, on the other hand, increased by about 26 to 28 percent in these four rural deciles. As shown in Rows 5 and 6 of Table 3, both the CPIAL general price index and the CPIAL food price index rose by exactly the same percentage over this period, so there was no change in food prices relative to the prices of non-food goods and services for these rural households.

In urban areas, the reduction in food-related spending has been even more marked, with all four deciles registering real declines in food expenditure. Table 4 shows that while poor, urban households have seen increases in real MPCE ranging from roughly 6 to 12 percent, real food expenditure has declined by approximately 3.5 to 6.5 percent between $1999-2000$ and 2009-2010. At the same time, real non-food expenditure has risen by roughly 23 to 31 percent. Row 6 of Table 4 shows that the CPIIW food price index rose slightly relative to the general CPIIW index (Row 5) 
over this period. Given the low initial levels of food expenditure in these urban households, however, it could have been expected that a positive income effect in favour of food consumption would more than compensate for this small change in relative prices.

Additional confirmation of this pattern of change in real food expenditures is provided by looking at the changes in per-capita calorie consumption in poor households over the period. Between 1999-2000 and 2009-2010, total calories consumed per capita have fallen for six out of the eight bottom deciles and only the lowest rural and urban deciles show a small increase in total calories consumed (Row 7, Tables 3 and 4). The overall pattern of per-capita calorie consumption in poor households is thus fairly consistent with the pattern of change seen in real food expenditures $^{10}$.

Taken together, these changes in real food expenditure and calorie consumption in poor households indicate that any increases in real income provided by either PDS subsidies or cash transfers may be spent almost totally on non-food goods and services, with food expenditure rising only marginally. Consequently, neither a reformed PDS nor cash transfers are likely to increase food consumption in poor Indian households. This finding therefore calls into question one of the basic assumptions underlying food subsidy policies in India - that poor households will prioritize food consumption over non-food goods and services (Sen, 2005).

\section{Objectives of the PDS and options for reform}

The analysis in Section 2 showed that the PDS already functions like a cash transfer to poor households. It also indicated that neither a reformed PDS nor cash 
transfers are likely to persuade poor families to either raise cereal consumption or increase spending on foods other than cereals.

Given these limitations of both the PDS and cash transfers, any proposal for reforming the current system must first establish exactly what the PDS is expected to accomplish. Different kinds of reforms may be indicated depending on whether the goal of the PDS is to reduce foodgrain prices, to simply provide a hand-out, or to increase food consumption in poor households. Accordingly, this section will begin by identifying the objectives of the PDS and will then make suggestions for how the current system may be reformed in relation to these objectives.

While the objectives of the PDS have not been clearly spelt out in any official document, a set of broad objectives can be discerned from the reports of the Indian Planning Commission and the statements of civil society groups (Planning Commission, 2002, 2005, 2008; Right to Food Campaign, 2011, 2013). It appears that the PDS is expected to play three main roles: firstly, to act as a price-stabilization and distribution mechanism for foodgrains; secondly, to provide a safety net for poor households; and thirdly, to increase food consumption and improve nutrition levels in poor families. Each of these roles is discussed separately below and the paper explores options for reform in line with these objectives.

\section{The PDS as a price-stabilization and distribution mechanism}

In its early years, the PDS was expected to counteract hoarding and provide a check on market forces, acting as both a price stabilization mechanism and general distribution system (see Planning Commission, 2005). Since private markets in India have developed rapidly in the last few decades, it might be presumed that there is no longer any need for a government-run distribution system. Nevertheless, it has been 
pointed out that even today, in remote areas, the PDS shop may be the only reliable, retail outlet - in its absence, villagers would have to travel long distances to buy foodgrains (Khera, 2011b; Puri, 2012). This indicates that the PDS may still be required to play a role in the distribution of grain, particularly in areas where markets and infrastructure are not fully developed.

With regard to price-stabilization, however, the government's attempts to manage food stocks actually appear to have raised market prices for grain in recent years. Government procurement of grain has been seriously unbalanced with Himanshu and Sen (2011) estimating, for instance, that grain procurement has exceeded drawdowns from the government's stocks by an annual average of over 12 million tonnes since 2007. Like Basu (2011), they suggest that the net effect has been a rise in market prices of grain while, at the same time, excess stocks of grain rot in the government’s storage facilities (Basu, 2011; Himanshu and Sen, 2011).

As shown in the previous section, even the poorest Indian households rely on sources other than the PDS for more than two-thirds of their total cereal consumption (see Tables 1 and 2). For households in the fourth MPCE decile, for example, purchases from the PDS constituted only 16 to 17 per cent of total cereal consumption. A rise in open market prices of grain thus hurts all consumers, including the poorest. ${ }^{11}$

Procurement of cereals is, of course, based, not simply on the requirements of the PDS, but also on the general agricultural and farmer support policies of the government. Nevertheless, a reduction in the quantities of grain distributed by the PDS, as proposed hereafter, should help to reduce the extent of government overprocurement and any related rises in the market price of cereals. 


\section{The PDS as a safety net}

In the eighties and nineties, the Indian government began to place greater emphasis on the role of the PDS as a safety net for the poor. By 1997, the PDS had been converted into a targeted system, with subsidies provided primarily to poor households. The World Bank (2011) estimates that the PDS is now 'easily the largest safety net program’ in the country (World Bank, 2011, pp. 8-9).

If the PDS's role as a safety net is limited to providing an income transfer or hand-out to poor families, then a shift to cash transfers would certainly be one option for reform. It has been argued that the use of electronic cash transfers together with biometric identification systems could significantly increase the benefits received by poor families (even tripling the amounts received by the bottom decile) by eliminating the corruption and waste prevalent in the PDS (Chaudhuri and Somanathan, 2011; Svedberg, 2012).

On the other hand, as opponents have pointed out, corrupt intermediaries may also find it much easier to divert cash and to trick or coerce often illiterate recipients (Ghosh, 2011). Since the advantages and disadvantages of cash transfer systems have already been debated at length elsewhere (see, for example, Kapur et. al., 2008; Kotwal et. al., 2011; Narayanan, 2011), this paper will not go into further detail on this issue.

However, the official stance seems to be that the PDS is not simply a hand-out or income transfer, but a safety net linked to food security. In a chapter titled 'Nutrition and the Social Safety Net', the Eleventh Plan document clarifies that the PDS is 'aimed at ensuring food security to all the people, especially the poor' (Planning Commission, 2008, p.134). As used here, the term 'food security' appears 
to signify that the state will ensure that all its citizens can consume a certain minimum quantity of food.

If the government's aim is to create a safety net for food security, as defined above, one possibility that could be explored is the substitution of free grain distribution for the current PDS subsidies. This could potentially reduce operational costs by reducing the quantities of grain handled by government agencies - if, for example, each eligible family were to receive $20 \mathrm{kgs}$ of free grain in lieu of $40 \mathrm{kgs}$ of grain at a 50 per cent subsidy. Since poor households sometimes do not have enough cash to purchase their entire PDS entitlement (Planning Commission, 2005), giving free food might also provide better protection against income shocks and cash-flow problems.

Another potential advantage of free food distribution over PDS subsidies might be that it would not require women in the household to control any cash in order to be assured of a minimum quantity of food. The literature on micro-credit in South Asia provides considerable evidence that women have very limited control over cash (Balasubramanian, 2013) and opponents of cash transfers have strongly argued that men may fritter cash away, leaving families without enough money to buy food (Ghosh, 2011; Puri, 2012). Additional research is needed in order to explore these issues further and arrive at a better understanding of the potential gains from free food distribution.

\section{The PDS as a nutrition programme}

Lastly, rather than providing just a minimum quantity of food as a safety net, the PDS is increasingly being called on to raise total food consumption and improve nutrition levels in poor households. The 'Right to Food Campaign', which is 
concerned about the high levels of malnutrition in the country, has argued for substantial increases in the quantities of subsidized grain provided by the PDS. The group also recommends the inclusion of foods such as pulses (a cheap source of protein), in the PDS rations (Right to Food Campaign, 2011, 2013). In policymaking circles too, there seems to be an expectation that the provision of foodgrains through the PDS should raise total cereal consumption in poor households and improve nutrition levels (Planning Commission, 2002, 2008).

In direct contradiction to these views, this paper has argued that the PDS has already provided larger quantities of cereals and given higher subsidies to poor families: however, this has not encouraged these families to consume more foodgrains. Consequently, providing poor households with even larger quantities of subsidized grain, in an attempt to increase cereal consumption, is futile. Moreover, as shown in Section 2.4, it cannot be assumed that any income transfers provided by the PDS (or via cash transfers) will be spent even partially on food.

If the objective is to increase food consumption and improve nutrition levels in poor families, therefore, the state must shift its efforts away from the PDS and/or cash transfers and towards more direct nutrition interventions. Integrated programmes, which include supplementary feeding for high-risk groups such as infants and pregnant/nursing women, as well as components like nutrition and hygiene education, are needed ${ }^{12}$. While the new National Food Security Bill does incorporate some of these elements, the PDS (with an option to shift to cash transfers in the future), still appears to be the major focus of the government's efforts.

This paper has highlighted the need for nutrition programmes to focus on additionality - as far as possible, the nutritional benefits they provide should not be offset by countervailing actions taken by households. As shown in the previous 
section, the additionality of the PDS is doubtful and the marginal propensity of poor households to consume food out of additional PDS subsidies may be extremely low. Other existing interventions, such as school-feeding programmes, might, however, hold greater potential.

Recent research provides much evidence of the additionality of school-feeding programmes for nutrition, showing that the benefits are not cancelled out by parents giving children less food at home (Afridi, 2010; Alderman and Bundy, 2012). While India already has a large, mandatory school-feeding programme, considerable attention and resources need to be devoted to improving implementation and the quality of meals (Bundy et al., 2009). Traditional school feeding could also be combined with initiatives like micro-nutrient supplementation and de-worming in order to have greater impact.

One of the more promising approaches might be to tie school-feeding and related nutrition programmes to educational reforms stemming from India's new Right to Education Act. This could multiply the impact of both kinds of interventions, since the educational benefits of school-feeding programmes include higher enrolment and attendance rates, as well as some improvements in learning capacity (Dreze and Kingdon, 2001; Alderman and Bundy, 2012).

\section{Conclusion}

The reluctance of poor families to increase food consumption, in spite of higher food subsidies and higher real incomes, might seem to indicate that their basic food requirements have already been met. On the contrary, the figures show that malnutrition rates in India remain very high. The Planning Commission points out 
that about half of all Indian children are underweight, while about 30 percent of adults have a body mass index which indicates malnutrition (Planning Commission, 2008).

In line with this evidence, there is a growing consensus that ensuring adequate nutrition should be one of the top priorities of the Indian government. The heated public debate about reform of the PDS reflects this view. However, that debate has focused largely on whether the corruption and inefficiency affecting the PDS can be reduced or whether it should be replaced by cash transfers. The issue of whether either of these measures will help to raise food consumption in poor households has not been adequately addressed. Unfortunately, as this paper has highlighted, the PDS already functions like a cash transfer, and neither an efficient, corruption-free PDS nor cash transfers can be relied on to increase food consumption in poor, Indian families.

While it should not be seen as a way of raising nutrition levels in poor households, the PDS may, nevertheless, have a role to play as both a distribution mechanism and safety net. Replacing larger quantities of subsidized food with more limited quantities of free food to poor families could convert the PDS into a more comprehensive and efficient safety net. The cost savings from such a move would also allow the government to increase its investment in more direct nutrition interventions, such as school-feeding programmes. Such focused nutrition programmes are essential to tackle the problem of malnutrition in India. 


\section{Appendix 1: List of Data Sources}

\section{National Sample Survey Reports}

All reports retrieved from: http://mospi.nic.in/Mospi_New/Admin/publication.aspx

1. National Sample Survey Office, National Statistical Organization (2012).

Household Consumption of Various Goods and Services in India (Report No. 541).

New Delhi: Government of India.

2. National Sample Survey Office, National Statistical Organization (2012).

Nutritional Intake in India (Report No. 540). New Delhi: Government of India.

3. National Sample Survey Office, National Statistical Organization (2011). Key

Indicators of Household Consumer Expenditure in India, 2009-2010. New Delhi:

Government of India.

4. National Sample Survey Organization (2007). Nutritional Intake in India, 20042005 (Report No. 513). New Delhi: Government of India.

5. National Sample Survey Organization (2007). Public Distribution System and Other Sources of Household Consumption, 2004-05 (Report No.510). New Delhi: Government of India.

6. National Sample Survey Organization (2006). Level and Pattern of Consumer Expenditure, 2004-05 (Report No. 508). New Delhi: Government of India.

7. National Sample Survey Organization (2001). Nutritional Intake in India, 19992000 (Report No. 471). New Delhi: Government of India.

8. National Sample Survey Organization (2001). Consumption of Some Important Commodities in India, 1999-2000 (Report No. 461). New Delhi: Government of India.

9. National Sample Survey Organization (2001). Level and Pattern of Consumer Expenditure in India, 1999-2000 (Report No. 457). New Delhi: Government of India.

\section{CPIAL and CPIIW Reports}

1. Labour Bureau, Ministry of Labour \& Employment, Government of India (2011). Consumer Price Index Numbers for Agricultural and Rural Labourers, Annual Report 2009-10. Retrieved from: http://labourbureau.gov.in/Reports_Old_Feb11.htm

2. Labour Bureau, Ministry of Labour \& Employment, Government of India (2012).

Consumer Price Index Numbers (for Industrial Workers), Annual Report 2010.

Retrieved from: http://labourbureau.gov.in/Reports_Old_Feb11.htm

3. Labour Bureau, Ministry of Labour \& Employment, Government of India (2010).

Consumer Price Index Numbers (for Industrial Workers), Annual Report 2009.

Retrieved from: http://labourbureau.gov.in/Reports_Old_Feb11.htm

4. Labour Bureau, Ministry of Labour \& Employment, Government of India (2006).

Consumer Price Index Numbers (for Industrial Workers), Annual Report 2005.

Retrieved from: http://labourbureau.nic.in/CPIW05 


\section{Notes}

${ }^{1}$ Throughout the paper, the terms 'foodgrains', 'cereals' and 'grain' are used interchangeably.

${ }^{2}$ However, this is likely to change after the passage of the new National Food Security Bill in September, 2013.

${ }^{3}$ The NSS reports contain both the quantity in kilograms and the value in rupees of purchases of rice, wheat and all/total cereals by households. Dividing the value by the quantity of purchases provides a 'unit value' or average price paid by households per kilogram of rice, wheat or total cereals. The use of unit-value prices for cereals is unavoidable since the official CPIAL and CPIIW reports have only recently started providing a sub-index of cereal prices for earlier periods, cereal price indices are not available. Also, the CPIAL and CPIIW reports do not provide prices for rice and wheat separately, but group them together with other cereals.

${ }^{4}$ The difference between the market price and PDS price of rice multiplied by the quantity of rice purchased by a household from the PDS, represents the nominal income transfer due to rice purchases; the calculation for wheat purchases is identical.

${ }^{5}$ Note that the growth rates of per-capita income based on these MPCE figures are generally acknowledged to be lower than the estimates of per-capita income growth arrived at by using the national income accounts (see Deaton and Dreze, 2009).

${ }^{6}$ Therefore, although the actual composition of households comprising the bottom four MPCE deciles may have altered somewhat during the 11-year period, this change in composition should not have reduced cereal consumption but actually have improved it, since households in every decile were richer by the end of the period.

7 'Total cereal consumption' here refers to consumption of rice, wheat and all other cereals, bought or received from any source, including the PDS.

${ }^{8}$ Note that for conditions 3, 4 and 5 and the related variables, the tests of significance are not relevant since the changes in these variables have been in the opposite direction to that expected. For instance, the analysis concludes that total cereal consumption in poor households has not increased (condition 5). Since the cereal consumption figures show a decline, non-significance would simply suggest that this decline was insignificant and that total cereal consumption had stayed constant - which is exactly what the analysis claims. Similarly, condition 3 only requires that relative cereal prices do not rise (the figures show a fall), and condition 4 that real incomes do not fall (the figures show a rise).

${ }^{9}$ The figures for total rice and wheat consumption (from all sources, including the PDS) are not shown in Tables 1 and 2. However, the analysis shows that the total quantity of rice and wheat consumed also declined between 1999-2000 and 2009-2010 for seven out of the eight deciles considered here. Even in the first rural MPCE decile, in which the total consumption of rice and wheat rose over this period, this rise was more than offset by a fall in the consumption of other cereals, resulting in a decline in total cereal consumption.

${ }^{10}$ Note that the pattern of per-capita calorie consumption in poor households may differ somewhat from the pattern of real food expenditure due to changes in the sources of calories. A shift from more expensive to cheaper sources of calories, for instance from fats to cereals, might cause per-capita calorie consumption to rise even if real food expenditure per capita was falling.

${ }^{11}$ Rural households too are increasingly relying on the market for cereal purchases. In 20092010, the ratio of home-grown produce to total consumption among rural households was just 25 percent for rice and 37 percent for wheat (National Sample Survey Office, 2013).

Moreover, these figures represent the average across all MPCE deciles - for the poorest rural households, who are least likely to own land, the share of home-grown produce in total consumption may be considerably lower.

${ }^{12}$ White and Masset (2007) suggest that the Tamil Nadu Integrated Nutrition Project is a successful example of such an integrated programme. 


\section{References}

Afridi, F. (2010). Child welfare programs and child nutrition: Evidence from a mandated school meal program in India. Journal of Development Economics, 92, 152-165. Ahmed, A.U. (2005). Comparing Food and Cash Incentives for Schooling in Bangladesh. Washington, DC: International Food Policy Research Institute.

Alderman, H. \& Bundy, D. (2012). School Feeding Programs and Development: Are We Framing the Question Correctly? The World Bank Research Observer, 27 (2), 204-221.

Balasubramanian, S. (2013). Why Micro-Credit May Leave Women Worse Off: NonCooperative Bargaining and the Marriage Game in South Asia. The Journal of Development Studies, 49 (5), 609-623.

Basu, K. (2011) India's Foodgrain Policy: An Economic Theory Perspective. Economic \& Political Weekly, XLVI, 37-45.

Breunig, R., Dasgupta, I., Gundersen, C. \& Pattanaik, P. (2001). Explaining the Food Stamp Cash-Out Puzzle (Food Assistance and Nutrition Research Report No. 12). Washington, DC: U.S. Department of Agriculture.

Bundy, D., Burbano, C., Grosh, M., Gelli, A., Jukes, M. \& Drake, L. (2009). Rethinking School Feeding: Social Safety Nets, Child Development and the Education Sector. Washington, D.C.: World Bank. Chaudhuri, A.R. \& Somanathan, E. (2011). Impact of Biometric Identification-Based transfers. Economic \& Political Weekly, XLVI (21), 77-80.

Currie, J. \& Gahvari, F. (2008). Transfers in Cash and In-Kind: Theory Meets the Data. Journal of Economic Literature, 46(2), 333-383.

Deaton, A. (2008). Price Trends in India and Their Implications for Measuring Poverty. Economic \& Political Weekly, 43 (6), 43-49.

Deaton, A. \& Dreze, J. (2009). Food and Nutrition in India: Facts and Interpretations. Economic \& Political Weekly, XLIV (7), 43-49.

Dreze, J. \& Khera, R. (2011, August 12). PDS leakages: the plot thickens. The Hindu. Retrieved from http://www.thehindu.com/opinion/lead/pds-leakages-the-plotthickens/article2351414.ece

Dreze, J. \& Kingdon, G. G. (2001). School Participation in Rural India. Review of Development Economics, 5 (1), 1-24.

Ghosh, J. (2011). Cash Transfers as the Silver Bullet for Poverty Reduction: A Skeptical Note. Economic and Political Weekly, XLVI (21), 67-71.

Himanshu \& Sen, A. (2011) Why Not a Universal Food Security Legislation? Economic \& Political Weekly, XLVI (12), 38-47.

Jha, S. \& Ramaswami, B. (2010). How can food subsidies work better? Answers from India and the Philippines (ADB Economics Working Paper Series No. 221). Manila: Asian Development Bank.

Kapur, D., Mukhopadhyay, P., \& Subramanian, A. (2008). The Case for Direct Cash Transfers to the Poor. Economic and Political Weekly, 43 (15), 37-43.

Khera, R. (2011a). India's Public Distribution System: Utilisation and Impact. The Journal of Development Studies, 47 (7), 1038-1060.

Khera, R. (2011b). Revival of the Public Distribution System: Evidence and Explanations. Economic \& Political Weekly, XLVI (44 \&45), 36-50.

Kochar, A. (2005). Can Targeted Food Programs Improve Nutrition? An Empirical Analysis of India's Public Distribution System. Economic Development and Cultural Change, 54 (1), 203-235.

Kotwal, A., Murugkar, M., \& Ramaswami, B. (2011). PDS Forever? Economic \& Political Weekly, XLVI (21), 72-76.

Kumar, P., Mruthyunjaya, \& Dey, M. M. (2007). Long-term Changes in Indian Food Basket and Nutrition. Economic and Political Weekly, XLII (35), 3567-3572. 
Mittal, S. (2007). What Affects Changes in Cereal Consumption? Economic and Political Weekly, 42(5), 444-447.

Narayanan, S. (2011). A Case for Reframing the Cash Transfer Debate in India. Economic and Political Weekly, XLVI (21), 41-48.

National Sample Survey Organization (2007). Public Distribution System and Other Sources of Household Consumption, 2004-05 (Report No.510). New Delhi: Government of India. Retrieved from: http://mospi.nic.in/Mospi_New/Admin/publication.aspx

National Sample Survey Office, National Statistical Organization (2013). Public Distribution System and Other Sources of Household Consumption (Report No. 545). New Delhi: Government of India. Retrieved from: http://mospi.nic.in/Mospi_New/Admin/publication.aspx

Ninno, C.D. \& Dorosh, P.A. (2003). Impacts of In-Kind Transfers on Household Food Consumption: Evidence from Targeted Food Programmes in Bangladesh. The Journal of Development Studies, 40 (1), 48-78.

Patnaik, U. (2010). On some Fatal Fallacies. Economic and Political Weekly, XLV (47), 8187.

Planning Commission, Government of India. (2002). Tenth Five Year Plan (20022007):Volume II. New Delhi: Oxford University Press.

Planning Commission, Government of India. (2005). Performance Evaluation of Targeted Public Distribution System (TPDS). New Delhi: Government of India.

Planning Commission, Government of India. (2008). Eleventh Five Year Plan (20072012):Volume II. New Delhi: Oxford University Press.

Puri, R. (2012). Reforming the Public Distribution System: Lessons from Chhattisgarh. Economic \& Political Weekly, XLVII (5), 21-23.

Radhakrishna, R. (2005). Food and Nutrition Security of the Poor: Emerging Perspectives and Policy Issues. Economic \& Political Weekly, 40 (18), 1817-1821.

Rao, H. C.H. (2005). Declining per-capita demand for foodgrains in rural India: causes and implications. In Rao, H. C.H. (Ed.), Agriculture, Food Security, Poverty and Environment: Essays on Post-reform India (pp.121-136). New Delhi: Oxford University Press.

Right to Food Campaign (2011). Right to Food. Economic \& Political Weekly, 46 (33), 21-23. Right to Food Campaign (2013). Note on replacing PDS with cash transfers (campaign material) Retrieved from http://www.righttofoodindia.org/pds/pds_campaign_material.html Sen, P. (2005). Of Calories and Things: Reflections on Nutritional Norms, Poverty Lines and Consumption Behaviour in India. Economic \& Political Weekly, 40 (43), 4611-4618.

Southworth, H. (1945). The Economics of Public Measures to Subsidize Food Consumption. Journal of Farm Economics, 27, 28-36.

Svedberg, P. (2012). Reforming or Replacing the Public Distribution System with Cash Transfers? Economic \& Political Weekly, XLVII (7), 53-62.

White, H. \& Masset, E. (2007). Assessing Interventions to Improve Child Nutrition: A Theory-Based Impact Evaluation of the Bangladesh Integrated Nutrition Project. Journal of International Development, 19, 627-652.

World Bank (2011). Social Protection for a Changing India: Volume I. New Delhi: World Bank. 
Table 1: Income transfer due to PDS; cereal prices and cereal consumption (RURAL)

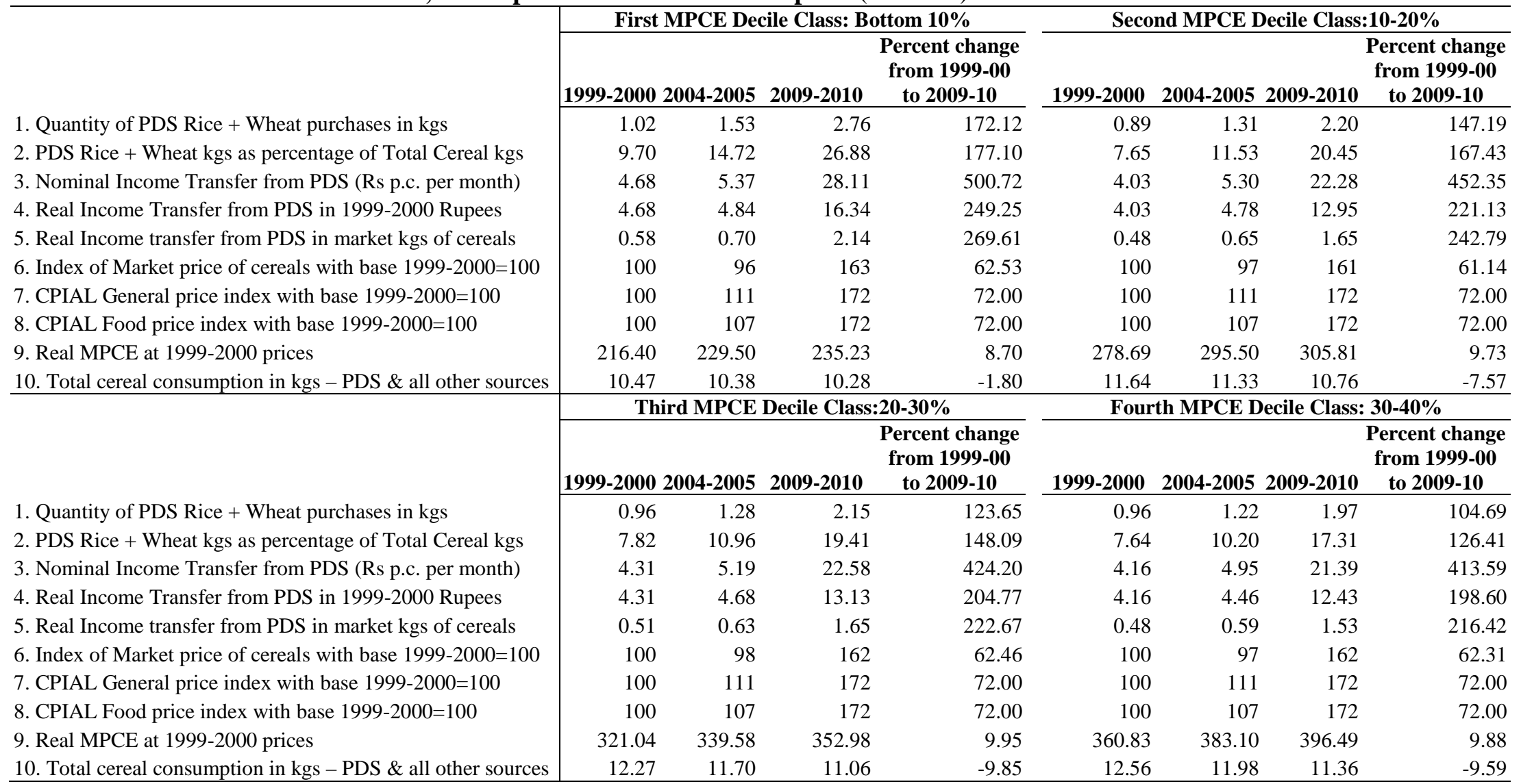

Notes: 1. Figures relate to monthly per-capita consumption and expenditure per household. 2. All values are in Indian rupees. 3. MPCE figures are based on the Mixed Recall Period (MRP) method for all 3 years.

Source: Author's calculations from various NSS and CPIAL Reports; see Appendix 1 for detailed list 
Table 2: Income transfer due to PDS; cereal prices and cereal consumption (URBAN)

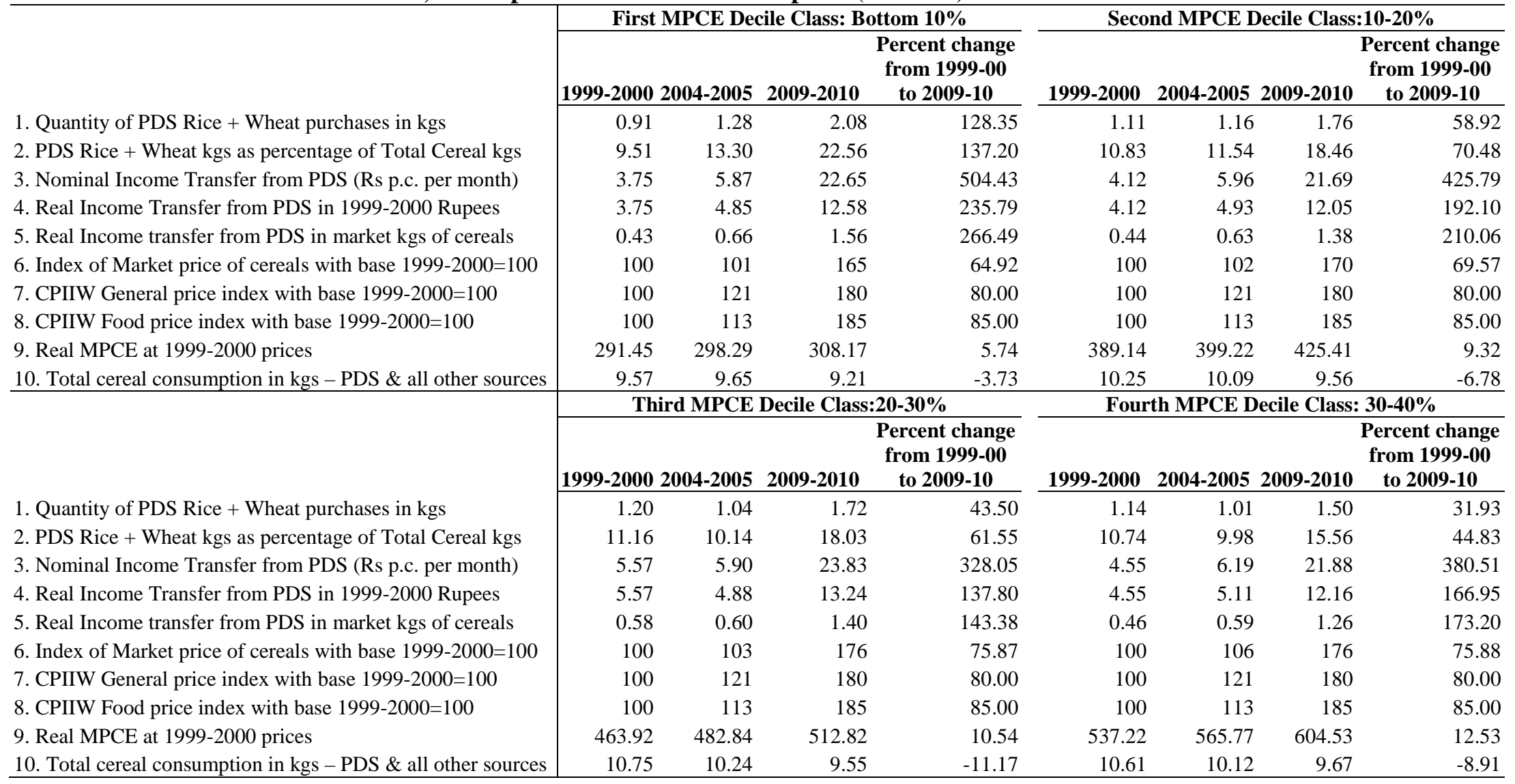

Notes: 1. Figures relate to monthly per-capita consumption and expenditure per household. 2. All values are in Indian rupees. 3. MPCE figures are based on the Mixed Recall Period (MRP) method for all 3 years.

Source: Author's calculations from various NSS and CPIIW Reports; see Appendix 1 for detailed list 
Table 3: Trends in Food and Non-food expenditure (RURAL)

\begin{tabular}{|c|c|c|c|c|c|c|c|c|}
\hline & \multicolumn{4}{|c|}{ First MPCE Decile Class: Bottom 10\% } & \multicolumn{4}{|c|}{ Second MPCE Decile Class:10-20\% } \\
\hline & $1999-2000$ & 2004-2005 & 2009-2010 & $\begin{array}{l}\text { Percent change } \\
\text { since 1999-2000 }\end{array}$ & 1999-2000 & 2004-2005 & 2009-2010 & $\begin{array}{l}\text { Percent change } \\
\text { since 1999-2000 }\end{array}$ \\
\hline 1. Real MPCE at $1999-2000$ prices & 216.40 & 229.50 & 235.23 & 8.70 & 278.69 & 295.50 & 305.81 & 9.73 \\
\hline $\begin{array}{l}\text { 2. Real Food expenditure at } 1999-2000 \text { prices } \\
\text { 3. Real Food expenditure as percentage of real MPCE at }\end{array}$ & 145.10 & 143.48 & 144.71 & -0.27 & 183.96 & 183.93 & 184.80 & 0.46 \\
\hline $1999-2000$ prices & 67.05 & 62.52 & 61.52 & -8.25 & 66.01 & 62.25 & 60.43 & -8.45 \\
\hline 4. Real Non-Food expenditure at $1999-2000$ prices & 71.31 & 91.19 & 90.52 & 26.95 & 94.73 & 118.19 & 121.01 & 27.74 \\
\hline 5. CPIAL General price index with base $1999-2000=100$ & 100 & 111 & 172 & 72.00 & 100 & 111 & 172 & 72.00 \\
\hline 6. CPIAL Food price index with base $1999-2000=100$ & 100 & 107 & 172 & 72.00 & 100 & 107 & 172 & 72.00 \\
\hline \multirow[t]{3}{*}{ 7. Calories (Kcal) consumed per-capita per day } & 1496 & 1476 & 1531 & 2.34 & 1733 & 1679 & 1703 & -1.73 \\
\hline & \multicolumn{4}{|c|}{ Third MPCE Decile Class: $20-30 \%$} & \multicolumn{4}{|c|}{ Fourth MPCE Decile Class: $30-40 \%$} \\
\hline & 1999-2000 & 2004-2005 & 2009-2010 & $\begin{array}{l}\text { Percent change } \\
\text { since 1999-2000 } \\
\end{array}$ & 1999-2000 & 2004-2005 & 2009-2010 & $\begin{array}{l}\text { Percent change } \\
\text { since 1999-2000 }\end{array}$ \\
\hline 1. Real MPCE at 1999-2000 prices & 321.04 & 339.58 & 352.98 & 9.95 & 360.83 & 383.10 & 396.49 & 9.88 \\
\hline $\begin{array}{l}\text { 2. Real Food expenditure at } 1999-2000 \text { prices } \\
\text { 3. Real Food expenditure as percentage of real MPCE at }\end{array}$ & 208.03 & 207.30 & 210.35 & 1.12 & 233.49 & 231.87 & 233.30 & -0.08 \\
\hline $1999-2000$ prices & 64.80 & 61.05 & 59.59 & -8.03 & 64.71 & 60.52 & 58.84 & -9.07 \\
\hline 4. Real Non-Food expenditure at $1999-2000$ prices & 113.00 & 139.75 & 142.62 & 26.21 & 127.34 & 159.59 & 163.20 & 28.16 \\
\hline 5. CPIAL General price index with base $1999-2000=100$ & 100 & 111 & 172 & 72.00 & 100 & 111 & 172 & 72.00 \\
\hline 6. CPIAL Food price index with base $1999-2000=100$ & 100 & 107 & 172 & 72.00 & 100 & 107 & 172 & 72.00 \\
\hline 7. Calories (Kcal) consumed per-capita per day & 1868 & 1800 & 1798 & -3.75 & 1957 & 1885 & 1908 & -2.50 \\
\hline
\end{tabular}

Notes: 1. All figures refer to monthly per-capita expenditure per household in Indian rupees; except calories consumed which are per-capita per day. 2. All expenditure figures are based on the Mixed Recall Period (MRP) method for all 3 years. 3. All nominal expenditure has been converted into real terms using the CPIAL General price index as deflator; except for Food expenditure which is deflated by the CPIAL Food price index.

Source: Author's calculations from various NSS and CPIAL Reports; see Appendix 1 for detailed list 
Table 4: Trends in Food and Non-food expenditure (URBAN)

\begin{tabular}{|c|c|c|c|c|c|c|c|c|}
\hline \multirow{5}{*}{$\begin{array}{l}\text { 1. Real MPCE at } 1999-2000 \text { prices } \\
\text { 2. Real Food expenditure at } 1999-2000 \text { prices } \\
\text { 3. Real Food expenditure as percentage of real MPCE at } \\
\text { 1999-2000 prices }\end{array}$} & \multicolumn{4}{|c|}{ First MPCE Decile Class: Bottom 10\% } & \multicolumn{4}{|c|}{ Second MPCE Decile Class:10-20\% } \\
\hline & $1999-2000$ & & 2009-2010 & $\begin{array}{l}\text { Percent change } \\
\text { since 1999-2000 }\end{array}$ & \multicolumn{4}{|c|}{ 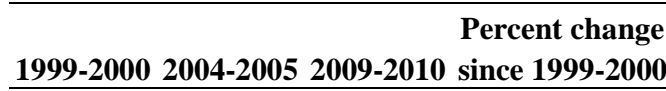 } \\
\hline & 291.45 & 298.29 & 308.17 & 5.74 & 389.14 & 399.22 & 425.41 & 9.32 \\
\hline & 186.67 & 183.05 & 174.58 & -6.48 & 240.41 & 234.49 & 228.72 & -4.86 \\
\hline & 64.05 & 61.37 & 56.65 & -11.55 & 61.78 & 58.74 & 53.76 & -12.97 \\
\hline 4. Real Non-Food expenditure at $1999-2000$ prices & 104.79 & 127.34 & 128.74 & 22.85 & 148.73 & 180.24 & 190.33 & 27.97 \\
\hline 5. CPIIW General price index with base $1999-2000=100$ & 100 & 121 & 180 & 80.00 & 100 & 121 & 180 & 80.00 \\
\hline 6. CPIIW Food price index with base $1999-2000=100$ & 100 & 113 & 185 & 85.00 & 100 & 113 & 185 & 85.00 \\
\hline \multirow[t]{3}{*}{ 7. Calories (Kcal) consumed per-capita per day } & 1526 & 1511 & 1544 & 1.18 & 1729 & 1687 & 1681 & -2.78 \\
\hline & \multicolumn{4}{|c|}{ Third MPCE Decile Class: $20-30 \%$} & \multicolumn{4}{|c|}{ Fourth MPCE Decile Class: $30-40 \%$} \\
\hline & $1999-2000$ & 2004-2005 & 2009-2010 & $\begin{array}{l}\text { Percent change } \\
\text { since 1999-2000 } \\
\end{array}$ & 1999-2000 & 2004-2005 & 2009-2010 & $\begin{array}{l}\text { Percent change } \\
\text { since 1999-2000 }\end{array}$ \\
\hline 1. Real MPCE at 1999-2000 prices & 463.92 & 482.84 & 512.82 & 10.54 & 537.22 & 565.77 & 604.53 & 12.53 \\
\hline $\begin{array}{l}\text { 2. Real Food expenditure at } 1999-2000 \text { prices } \\
\text { 3. Real Food expenditure as percentage of real MPCE at }\end{array}$ & 278.31 & 270.39 & 262.75 & -5.59 & 309.06 & 306.52 & 298.34 & -3.47 \\
\hline 1999-2000 prices & 59.99 & 56.00 & 51.24 & -14.59 & 57.53 & 54.18 & 49.35 & -14.22 \\
\hline 4. Real Non-Food expenditure at 1999-2000 prices & 185.62 & 230.33 & 242.77 & 30.79 & 228.16 & 279.51 & 297.91 & 30.57 \\
\hline 5. CPIIW General price index with base $1999-2000=100$ & 100 & 121 & 180 & 80.00 & 100 & 121 & 180 & 80.00 \\
\hline 6. CPIIW Food price index with base $1999-2000=100$ & 100 & 113 & 185 & 85.00 & 100 & 113 & 185 & 85.00 \\
\hline 7. Calories (Kcal) consumed per-capita per day & 1912 & 1833 & 1749 & -8.53 & 1968 & 1856 & 1831 & -6.96 \\
\hline
\end{tabular}

Notes: 1. All figures refer to monthly per-capita expenditure per household in Indian rupees; except calories consumed which are per-capita per day. 2. All expenditure figures are based on the Mixed Recall Period (MRP) method for all 3 years. 3. All nominal expenditure has been converted into real terms using the CPIIW General price index as deflator; except for Food expenditure which is deflated by the CPIIW Food price index. 
